\title{
CLASSROOM INSTRUCTION AND WORKPLACE PRACTICE: VALUES THAT SHAPE TEACHING AND PERFORMANCE STANDARDS
}

\author{
DIANA WEGNER \\ DOUGLAS COLLEGE, BRITISH COLUMBIA
}

Instructors in every field are faced with the ongoing challenge of determining appropriate curricula, pedagogy, and evaluation criteria, and they must justify these choices to colleagues and administrators. In the hybrid field of workplace writing instruction, this undertaking can be particularly daunting because of shifting assumptions about the relevance of curriculum to workplace practice. These fluctuations may be the result of changes in practice, dissatisfaction with employee performance, or corporate, political and educational preferences. Instructors are continually reappraising decisions as to what degree they should be invoking workplace practice on the one hand, and academic notions and standards on the other.

This responsiveness to of ten disparate, external factors hinders the integrity of workplace writing as a discipline. The existence of competing rhetorics and values results in a fragmentation of the discipline. As Charles Bazerman reminds us, we don't live up to the criteria of Kuhn's definition of a "disciplinary matrix": there are neither clearly identifiable, "shared features" nor a "neutral terminology" that would facilitate "mutually acceptable criteria" (Kuhn in Bazerman 1983). The result is often a lack of conjunction between theory, teaching methods, and evaluation standards. Sometimes pedagogy is applied independently of theoretical orientation; or evaluation, which is often loosely based on first year composition criteria, is then adjusted in response to unintegrated input from career program instructors and employers. 
Some theorists and practitioners are explicit and self-examining about the values that inform their approaches. Others merely assume a certain tacit framework for teaching goals and strategy. This is certainly the case for writing evaluation in general. As Lester Faigley (CCC DEC/89) points out, the literature on writing evaluation "tends to assume that a broad consensus exists about what constitutes good writing and that we can recognize good writing when we see it" (395). Faigley notes that "each judgment ... is made from some notion of value (emph. minel, usually a notion that is widely shared within a culture" (395), and that most research since the mid 1960's "has not told us much about exactly what it is that teachers value in student writing" (395).

The following example will perhaps illustrate the problem for writing instructors. Recently Gary Sloan has compared definitions of error in classroom handbooks to error type and incidence in professional writing of the journalist essay genre ("Frequency" 299-308). Like many he seems to suggest that where differences exist (and many do) the realworld practices of professional writers should be the standard. Both Sloan and a respondent to his article, Robinson, agree that in such cases students should not be penalized for errors that professionals make. Sloan further advises that writing instructors should maintain "habitual observation" of professional writing practices ("Reply" 241). This "habitual observation"--and the standard it implies--is typical of the assumption that pedagogy and evaluation should be driven by workplace practice. The basis for this assumption, however, is not offered in the literature. The workplace is almost a sacrosanct force in some research and theory, so that in the name of this assumption the values and beliefs that permeate the workplace are often uncritically accepted, and can become problematic for instructors. Moreover there are pedagogical arguments against adopting professional practices as standards in the classroom. For example, because error-commission is necessary to the learning process, many believe teachers must tolerate error as their students reach beyond themselves to acquire new knowledge and skills.

To focus on this problem of conflicting and sometimes unstated standards, I have examined samples of discourses that vary in terms of their assumptions about standards, yet influence our instructional values and often seriously complicate evaluation. These discourses seem to 
promote standards and pedagogies that can be adapted to their respective values, but which may not support theoretical principles or be the most appropriate strategies. They fall into two general types, each characterized by a dominant, though not single, value system: the first is what Carolyn Miller has termed "the rhetoric of 'the world of work" ("What's Practical" 24) or more simply here "of the workplace"; and the second the rhetoric of ethical-humanism. The debate between proponents of these two rhetorics usually revolves around a number of values and goals. Those who privilege performance criteria and pedagogies based on workplace practice refer to usefulness, correct and incorrect practices, corporate culture, and scientific studies of the cognitive strategies of experts. On the other side of the debate, humanistic rhetoricians refer to critical awareness, truth, good conduct, citizenship, and democracy: they favour teaching conventional, decontextualized knowledge that will lead to truth and wisdom. The first model is attuned to the "real world" of work; the second to a world that is patently ideal but which is conceived as worth striving towards. There have been proposals for building bridges between these communities (the rhetoric of "bridge-building"), but such proposals are rarely realized because the opposing rhetorics tend to eventually reconstitute themselves and resist these alternative discourses promoting a shared ground.

Ultimately contradictions between rhetoric about standards and instructional practices persist, for neither of the opposing value systems modifies its rhetoric to incorporate and legitimate those pedagogies it recommends. Notably, although the terminology may change--as questions of relevance, transference and literacy regularly resurface-instructors regularly respond, communicating a sense that they feel implicated and responsible.

Because pedagogies are often appropriated from other sources and are not always strongly connected at the theoretical level, the same strategies can be promoted by opposing value systems for different reasons. For example, social context theory, the process approach, sociocognitive blends such as "cognitive apprenticeship," and expertise theory have all been incorporated by both rhetorics. 
The following discussion is arranged according to these opposing value systems into two parts: first the rhetoric of workplace writing, and second the rhetoric of ethical-humanism. This discussion is based on a selection of excerpts from recent publications related to the teaching of workplace writing in terms of the rhetorics or values they imply or claim, and the teaching strategies they recommend.

\section{THE RHETORIC OF THE WORKPLACE}

The belief that classroom standards for teaching workplace writing should be based on workplace practice (partly or wholly) exists implicitly in many textbooks and often explicitly in the work of researchers and theorists. The following is a selection of excerpts from current textbooks in which workplace practice seems to be valued at least in part as an important influence on determining standards. In some cases it eclipses academic criteria; in others both types of criteria are posited as important.

Text 1 (1990). The preface tells us the focus is on "career advancement" and that, based on the study of a bonafide employee, the text shows "how an employee brainstorms, researches, drafts, and revises an internal proposal" (Kolin viii).

Text 2 (1991). The authors state in the preface that "The purpose of the book is to train ... students and professional in the written communication required of practicing professionals and managers on the job" (Mathes and Stevenson vii). To this end "numerous examples drawn from the real work of business, industry, and government" and an extended case study provide a "real-world context" for assignments (viii). The inclusion of a new chapter on collaborative writing is based on the study of how employees write on the job.

Text 3 (1984). In the second chapter of this text, the reader is informed of three different categories of writing, based on workplace criteria of quality: 
Excellent technical writing--the kind of writing that will gain points for you in on-the-job situations; the kind of writing that will lead to raises, promotions, and other recognition of the excellence of your work; the kind of writing that will consistently get your recommendations accepted, your proposals funded, and your reports praised.

Adequate technical writing--the kind of writing that will keep from embarrassing you in on-the-job situations; the kind of writing that will be accepted and passed on, largely without comment; the kind of writing that won't hurt you but certainly won't help you.

Unacceptable technical writing--the kind of writing that you'll get back to do over again until it's right; the kind of writing that will clamp a ceiling on all your other technical skills; the kind of writing that will be a constant impediment to your professional growth. (Stratton 17-18).

Other texts expressly combine a workplace emphasis with more traditional academic components.

Text 4 (1991). This textbook provides "[e]xercises [that] parallel the writing demands students will face both in college and on the job" (Lannon xxi). We are told that "readers will find strategies used routinely by technical communicators," but that the text also provides "a balance of examples from the workplace and from student writing" (xxi). Among additions to this edition is a "new chapter on persuasion, based on current research in rhetoric and social science, communication, and workplace practices" (xxii). This edition also includes "[m]ore projects... [which] offer practice in the kinds of collaborative writing often done in the workplace" (xxiii).

The Instructor's Manual that accompanies this textbook recommends an "informal-contract grading system." Part of the rationale for this practice is that "[p]eople who write 
on the job are not graded $\mathrm{C}+$ or $\mathrm{B}-$ : the report or letter is unacceptable, acceptable, or superior" (16).

Text 5 (1991) implies standards based on both academic and workplace practices: curriculum covers basic writing and general principles of usage for a variety of disciplines. The long list of acknowledgements to organizations that provided materials for use in this text also suggests broad workplace input (Treece).

Text 6 (1989). In comments "to the instructor" this text is described as follows: "Through a reader-centred process approach, the chapters provide explanations, examples, case studies, and exercises for technical writing students of all disciplines" (Samuels vii).

Text 7 (1984) covers the writing process and skills for both academic and occupational students "whose jobs will, or already do, require writing skills" (Oliu, Brusaw, and Alred v). Rhetorical strategies are also covered, with job-related examples from a wide range of occupations.

Text 8 (1987). One of the "major goals" of this text is "to devise a framework that will help us as teachers to integrate our instruction in the standard forms of technical communication with the rhetorical and process-oriented approach" (Anderson vii). The text "covers both the processes and products of writing on the job," so that students can "learn what readers expect, desire, and need in various typical on-the-job situations" (iii).

Some researchers give explicit emphasis to workplace practice as a pedagogical guideline, especially in ethnographic studies. For example Odell, Goswami, Herrington and Quick (1983) state that above all we must ask ourselves, "Are my theory and teaching procedures consistent with what writers [in the workplace] actually do?" (17) They point out that "the contexts for and the consequences of this writing can be 
substantially different from what one encounters in experimental tasks designed by a teacher or researcher" (19), and they recommend changes that would allow for "immediate, insistent feedback" by "someone who was genuinely willing to be informed or persuaded by the writing rather than someone who was simply interested in identifying the formal features of the writing" (38). In terms of assignments, they include both "writing tasks people actually do as a normal part of their day-to-day work" and process-oriented, "teacher-designed, experimental tasks" (18).

Reporting on a later workplace-based study (1985), Odell disclaims that "there is no basis for suggesting that all the findings of this study should influence our teaching" (274), but generally he seems to emphasize workplace practice as the touchstone for the classroom. He asserts that his study of how a real analyst works on the job "may modify our teaching in many ways" and "change the kind of analytic procedures we teach students to use" (276). That is, instead of the general analytical procedures of the process approach, he suggests we need the contextualized "eclectic procedures" utilized by workplace writers. In the same publication (Writing in Nonacademic Settings), Lester Faigley describes how the social context approach is appropriate for instruction in workplace writing. His emphasis on the differences between academic and workplace writing tasks (233) implies a deficiency such that pedagogy should fall into line with workplace practice.

Similarly, in a 1987 study of writing courses for secondary students in occupational training programs (unpublished conference paper), Timothy Rush indicates concern over the "discrepancy between what is taught in school and the actual demands for writing observed in workplace and training environments" (5). And, in a 1985 College Composition and Communication article, Elizabeth Tebeaux notes that "surveys of employees in a wide range of organizations and job categories have defined important communication skills that many courses in business, technical, and science writing are not providing" (424). She urges teachers to "constantly assess course content by continuing to ask ... students already on the job, 'How useful are the skills you learned? How can we make our writing courses more relevant in preparing students for the workplace?"' (427). Her recommended curriculum is a mixture of 
academic-based generic skills and field-related content that students would bring to the classroom themselves.

The influence of workplace practice on standards has most recently emerged in the promotion of the "cognitive apprenticeship" model. This model is based on studies of the cognitive strategies that real-world writers use and on expertise theory, also based on studies of professionals. It leads to recommendations for a workplace based pedagogy in which the instructor models writing expertise and tutors student-apprentices as they gradually gain basic competence. In two recent College Composition and Communication articles the model has been incorporated by Carter (1990) as a way to bridge the gap between cognitive and social approaches in college writing instruction, and it has been optimistically endorsed for its bridge-building potential by Berkenkotter (1991). Similarly, T. Rush recommends the adoption of cognitive apprenticeship for writing courses in vocational programs, where English and vocational educators can collaborate, and where workplace practices would guide instruction.

The textbook and research-based sources cited here are problematic in two ways. They betray an uncritical deference towards workplace practice, and they endorse an unexamined mixture of academic and nonacademic standards.

\section{THE RHETORIC OF ETHICAL-HUMANISM}

Ethical-humanism is largely inherited from classical rhetoric, with its various emphases on ethical concerns, but has been reinterpreted and modified by a number of influences, of which enlightenment concepts of the individual and freedom are particularly notable. Its more recent roots are in Arnold, Eliot, Weaver and Booth in their concern to inculcate in students the ability to judge and critique practices in the interests of developing social responsibility ("Citizenship" and "democracy" are key words in this rhetoric.)

Typical of efforts to reconceptualize classical values in contemporary rhetorical theory is Kate Ronald's 1990 article in Rhetoric Review where 
she argues for a re-examination of current personal and public discourse in terms of classical rhetoric. Ronald calls for a re-integration of the personal (the individual ethos, which compels the questioning of values, and the search for truth) into public discourse, and a re-instatement of the classical, educational triad of rhetoric, knowledge, and virtue (4546). One can see the influence of such notions in the thinking of technical writing theorists. Carolyn Miller, a technical writing specialist and rhetorician, argues for an ethical dimension in support of humanistic instruction in technical writing classrooms. In an early article (1979) she maintains that "lolur teaching of writing should present mechanical rules and skills against a broader understanding of why and how to adjust or violate the rules, of the social implications of the roles a writer casts for himself or herself. ..., and of the ethical repercussions of one's words" (617). Miller's stance here is primarily in reaction to colleagues and others who would trivialize instruction in workplace writing. We find a similar stance in Elizabeth Harris's recommendation of Kinneavy's theory of discourse as a basis for technical writing instruction, in order to give it "intellectual depth" and respectability (629-30).

Miller develops her critique and later (1989) shifts her focus to rhetorics of the workplace that assume utility and practice as primary standards. She cautions against an "uncritical" acceptance of workplace practices as standards of performance, noting the contradiction in accepting workplace practices as norms: first, surveys show that graduates have inadequate writing skills on the job; second, there is no consensus on standards within many professions or careers (15-16, 20); and third, there is sometimes the tendency to invoke criteria based on meeting manpower needs (20). Miller argues for a curriculum that would include "questions about whose interests a practice serves and how we decide whose interests should be served" (18). She extends her argument through an elaborated definition of praxis which is geared for "the good of the community" (23-24). The resulting pedagogy would promote knowledge of nonacademic, professional practices, but would also include academic practices to "provide a standpoint for inquiry into and criticism of nonacademic practices" (23).

Susan Wells provides another critique of workplace-based standards (1986). She criticizes the frequently ad hoc application of teaching 
strategies in technical writing classrooms, and is most denigrating of instructors who support the "ideology of technical writing" and endeavour to make their disciplines ever more responsive to industry and the corporate world without examining their role in promoting the interests of these users. Such instructors she labels "academic counterparts to the corporate communications officer," who in the name of the "principle of service" give themselves up to "use" (247). She also finds fault with the process model for its unexamined adoption of expert cognitive strategies as prescriptive for novice writers. Yet she equally criticizes the conventional humanistic, academic view of technical writing instruction for its global, idealized perspective, and for its elitism, what she describes as a "disturbing mandarin tone of regret for a past when the university was uncontaminated by social life" (246). Wells proposes an alternative in Habermas' theory of communicative competence and a corresponding pedagogy of discourse analysis, inquiry and argument (2627264).

In a somewhat different critique of adopting standards from workplace practice, David Dobrin urges teachers to "question the value of what [they] do" instead of relying on the poor guide of common sense which is often based on unexamined, "deeply held" values $(1983,248)$ Like Wells, he urges teachers to "suspect [them]selves" and study "the practice" and "relations of power" of all groups involved in technical writing (248). Dobrin is unforgiving of those technical writing teachers who he judges instinctively think of their job as "morally neutral" (1985, 148). In an interesting turn, he focuses his criticism on Miller for not casting her moral purposes in the appropriate context: "As long as Miller and others leave the pragmatic purposes intact, as long as we continue to talk about skills and needs, talk about humanistic rationales will sound muddle-headed" (156). He recommends instead that teachers give up the role of "master"--for practitioners are the real experts; and that "administrators, engineers, and industry be taught that fobbing off responsibility entirely on teachers (by talking about skills they need to

${ }^{1}$ The effects of pressure exerted by critiques such as Miller's and Wells' is attested to by the appearance of appendices or additional chapters on ethics in recent textbooks (see for example Lannon, 1991; Mathes and Stevenson 1991; and Treece, 1991). 
teach) is not a good idea" (157). In other words the ethical focus should be on what teachers can in good conscience assume of their authority and expertise.

While there is an adversarial tone in some humanistic critiques of workplace driven instruction, others who are concerned about the question of values do not express the same alarm. For example, in Jean Lutz's recent study of how writers acquire corporate culture, she recommends a pedagogy that would help student-writers contextualize their writing while learning how to access the codes and practices of organizations (1989). But she also offers a polite qualification. Having observed job dissatisfaction resulting from conflicts between writer and corporate values, she advocates more managerial openness to changes in values and processes that govern writing, so that writers can make constructive contributions to organizational change (130-32). Such a recommendation would, however, no doubt be considered ineffectual by many ethicalhumanists.

In general, ethical-humanist rhetoric seems to be based on a philosophical belief that inculcating employees into organizational culture is a matter of coercion, of one-way communication where differences in values are irrelevant and only obedience to authority is required; and that the academic, exploratory, and consensual nature of inquiry and argument is a more ethical means of persuasion.

A number of theorists recommend bridging this gap. Kristen Woolever expresses concern about "the gap between academe and industry" (3). While endorsing workplace practice (teachers need to "reevaluate [their] methods" because their "pre-professional" students will move into nonacademic settings [4]), at the same time she recommends that industry and academe respect differences, form teaching partnerships, and generally balance the process model (seen as academically driven) with a product or "real-world" model. Similarly, Theresa Enos, a rhetorician, sketches out a humanistic approach to teaching technical writing, with both a strong emphasis on ethics, as well as community coordination to facilitate on-site "real" writing tasks. She believes it is important to counter alienation and mistrust between individuals and institutions, but to do so through "partnerships between public and 
private sectors," through "consensus building," and through collaboration (107). This view is also expressed by consultants Rush and Evers in their 1986 report, Making The Match, on how Canadian employers and university graduates perceive "the adequacy of university education for employment" (1). Researchers found that employers feel their employees lack oral and written communication competence, and believe that "university education and subsequent corporate training should be thought of as a single process cooperatively managed" (2).

In opposition to such ameliorative recommendations are calls for a total divorce. David Dobrin's solution is to completely sever writing instruction from training in the workplace. This is a strong stance, but he does identify the central problem: the presumption of expertise many instructors do not possess.

This problem is usually addressed by deploring the qualifications of workplace writing instructors, and by stipulating a rigorous set of qualifications that most such instructors lack. Charles Stratton, one such advocate, states, "I regard people who hold bachelor's or master's degrees in science or engineering and Ph.D. degrees in Technical Communication or related fields as representing the primary level of educational qualification for teaching technical writing" (60-61). He characterizes those at the low end of the instructor scale as "people with graduate degrees in literature, composition and rhetoric, or journalism, or some field of science or engineering who have taken some graduate course work in technical communications or publications production or who have completed a graduate-level workshop or summer program in teaching technical or scientific writing" (61).

It may not be realistic to expect instructors to be all these things. Some instructors might argue that what is important is that they teach what they know how to teach, and that they judge their students' performance according to standards they can defend in terms of their expertise. If writing instructors really believe technical, career, and business students can benefit from such instruction, it would be important to provide sound evidence to opponents. One might therefore pursue a modified version of Dobrin's recommendation instead of attempting to straddle disparate value systems. 
Workplace writing instructors might also endeavour to ease the rocky transition from the classroom to the workplace by persuading employers of the serious difficulty of accomplishing both generic and contextualized learning, and by articulating for them the appropriate level of performance they can expect from graduates. There is support for such a position in the model of expertise developed by Dreyfus and Dreyfus (1986). They conclude that, at the juncture where the advanced beginner (the second of five stages leading to expertise) is prepared to be apprenticed to an expert, classroom practice is not helpful: the ensuing stages of competence, proficiency and expertise can be achieved only over time as a result of experience on the job. Expertise theory thus supports the contention of some instructors that employers are often misled by the willingness of instructors to transfer workplace models and input into classrooms, for this implies instructors have the expertise to apprentice practitioners. Following Dobrin then, workplace writing instructors could reverse the expectation that they should take on the onerous task of preparing students expressly and particularly for the workplace, and ask that employers take responsibility for apprenticing their own workers. In effect, this would entail a historical reversal of the nineteenth century shift from workplace to school-based instruction in apprentice-level knowledge.

Instructors and employers alike often zealously adopt a commodity mentality towards graduates that would have classrooms turn out complete and perfect products for employer consumption, that is employees who are "job-ready". A friendlier adaptation of Dobrin's solution might therefore be attractive to instructors who experience frustration as a result of this view.

\section{CONCLUSION}

Persistent dissatisfaction with technical writing instruction and performance comes from both academic and nonacademic communities. Such dissatisfaction usually leads to a comparison of content and strategies between academia and the workplace, and a catalogue of differences and deficiencies. While curricular and pedagogical adjustments are necessary in any field, for workplace writing 
instructional integrity is particularly problematic. The tensions described here tend to become deflected temporarily, and transmuted by other issues such as literacy, readiness of graduates, studies of corporate and school cultures, and ad hoc innovations in teaching. Yet, fundamental differences in attitudes towards standards persist.

The comments analyzed here illustrate three different responses to these conflicts:

1. A relatively untroubled accommodation of employer input in curricular design and teaching strategies.

2. Concern, dismay, or resistance to adopting workplace practices as standards in the classroom, and the accompanying promotion of a humanist theory and pedagogy.

3. A desire to incorporate both academic and nonacademic curriculum and pedagogy, either to avoid conflict or to pursue a meaningful resolution.

Whatever course the discipline of technical writing follows, the problem of conflicting values must be addressed, and a common vocabulary established. Such common ground would enable negotiation between what are at base conflicting ideologies, and help instructors develop reliable and sound evaluation criteria. It would also be a step towards developing the theoretical unity necessary to create a disciplinary matrix for technical writing.

As a first step we might ask ourselves what in fact we are responding to in these rhetorics that then develops into our experience of conflicting pressures. For there is a gesture in these discourses that names us and gives us a role that we accept. To borrow Althusser's words, we are all "interpellated" by discourse (173); that is, in the same instant that we are called (to action), we also respond. It is this moment of response to these rhetorics that we need to problematize if we are to teach and evaluate with integrity. 


\section{BIBLIOGRAPHY}

Althusser, Louis. "Ideology and Ideological State Apparatuses." Lenin and Philosophy. Trans. Ben Brewster. New York: Monthly Review Press, 1971.

Anderson, Paul V. Technical Writing. New York: Harcourt Brace Jovanovich, Inc., 1987.

Bazerman, Charles. "Scientific Writing as a Social Act: A Review of the Literature of the Sociology of Science." New Essays in Technical and Scientific Communication. Ed. Anderson, et al. Farmingdale, N.Y.: 1983.

Berkenkotter, Carol. "Paradigm Debates, Turf Wars, and the Conduct of Sociocognitive Inquiry in Composition." CCC May 1991: 151-169.

Berlin, James. "Rhetoric and Ideology in the Writing Class." CCC Sept. 1988: $477-494$.

Blicq, Ron s. Communicating at Work. Scarborough: Prentice-Hall Canada Inc., 1991.

Blicq, Ron S. Guidelines for Report Writing. 2nd ed. Scarborough: Prentice-Hall Canada Inc., 1990.

Brown, John Seely, Allan Collins, and Paul Duguid. "Situated Cognition and the Culture of Learning." Educational Researcher Jan.-Feb. 1989: 32-42.

Carter, Michael. "The Idea of Expertise: An Exploration of Cognitive and Social Dimensions of Writing." CCC Oct. 1990: 265-286.

Collins, Allan, John Seely Brown, and Susan E. Newman. "Cognitive Apprenticeship: Teaching the Crafts of Reading, Writing, and Mathematics." Knowing, Learning and Instruction. Ed. L.B. Resnick. Hillside, N.J.: Erlbaum, 1989. 
Connors, Robert J. "The Rise of Technical Writing Instruction in America." J. Tech. Writ. and Comm. 12 (1982): 329-352.

Dobrin, David N. "What's the Purpose of Teaching Technical Writing." Tech. Writ. Teacher Fall 1985: 146-162.

Dobrin, David N. "What Technical About Technical Writing?" New Essays in Technical and Scientific Communication: Research, Theory, Practice. Ed. P. Anderson, John Brockman, and Carolyn R. Miller. Farmingdale, N.Y.: Baywood Publishing Company, Inc., 1983.

Dreyfus, Hubert L. and Stuart E. Dreyfus. Mind Over Machine. New York: The Free Press, 1986.

Enos, Theresa. "Rhetoric and the Discourse of Technology." Worlds of Writing. Ed. Carol Matalene. New York: Random House, 1989.

Faigley, Lester. "Judging Writing, Judging Selves." CCC Dec. 1989: 395412.

Faigley, Lester. "Nonacademic Writing: The Social Perspective." Writing in Nonacademic Settings. Ed. Lee Odell and Dixie Goswami. New York: Guilford, 1985.

Harris, Elizabeth. "Applications to Kinneavy's Theory of Discourse to Technical Writing." CE Feb. 1979: 625-632.

Kolin, Philip C. Successful Writing at Work. 3rd ed. Toronto: D.C. Heath and Company, 1990.

Lannon, John M. Technical Writing. 5th ed. New York: Harper Collins Publishers, 1991.

Lutz, Jean Ann. "Writers in Organizations and How They Learn the Image: Theory, Research, and Implications." Worlds of Writing. Ed. Carolyn B. Matalene. New York: Random House, 1989. 
Mathes, J.C. and Dwight W. Stevenson. Designing Technical Reports. 2nd ed. New York: Macmillan Publishing Company, 1991.

Miller, Carolyn R. "What's Practical About Technical Writing?" Technical Writing: Theory and Practice. Ed. B.E. Fearing and W. Keats Sparrow. New York: MLA, 1989.

Miller, Carolyn R. "A Humanistic Rationale for Technical Writing." CE Feb. 1979: 610-617.

Odell, Lee, Dixie Goswami, Anne Herrington, and Doris Quick. "Studying Writing in Non-Academic Settings." New Essays in Technical and Scientific Communication. Ed. P. Anderson, John Brockmann, and Carolyn Miller. Farmingdale, N.Y.: Baywood Publishing Company, Inc., 1983.

Odell, Lee. "Beyond the Text: Relations between Writing and Social Context." Writing in Nonacademic Settings. Ed. Lee Odell and Dixie Goswami. New York: Guilford, 1985.

Oliu, Walter E., Charles Brusaw, and Gerald Alred. Writing That Works. 2nd ed. New York: St. Martin's Press, 1984.

Robinson, William S. "Response to Gary Sloan." CCC May 1991: 239-240.

Ronald, Kate. "A Reexamination of Personal and Public Discourse in Classical Rhetoric." Rhetoric Review Fall 1990: 36-48.

Rush, James C. and Frederick T. Evers. Making the Match: Canada's University Graduates and Corporate Employers. Montreal: Corporate-Higher Education Forum, 1986.

Rush, Timothy. "Writing and Working: Instructional Emphasis Versus On-the-Job Demands." Ms. University of Wyoming.

Samuels, Marilyn Schauer. The Technical Writing Process. New York: Oxford University Press, 1989. 
Sloan, Gary. "Reply." CCC May 1991: 240-241.

Sloan, Gary. "Frequency of Errors in Essays by College Freshmen and by Professional Writers." CCC Oct. 1990: 299-308.

Stratton, Charles R. "Qualifications for Teaching Technical Writing." TETYC Feb. 1991: 59-64.

Stratton, Charles R. Technical Writing. New York: Holt, Rinehart and Winston, 1984.

Tebeaux, Elizabeth. "Redesigning Professional Writing Courses to Meet the Communication Needs of Writers in Business and Industry." CCC Dec. 1985: 419-428.

Treece, Marla. Successful Communication for Business and the Professions. 5th ed. Boston: Allyn and Bacon, 1991.

Wells, Susan. "Jurgen Habermas, Communicative Competence, and the Teaching of Technical Discourse." Theory in the Classroom. Ed. Cary Nelson. Urbana: University of Illinois Press, 1986.

Woolever, Kristin R. "Coming to Terms With Different Standards of Excellence for Written Communication." Worlds of Writing. Ed. Carolyn B. Matalene. New York: Random House, 1989.

Diana Wegner teaches writing (Communications) at Douglas College and is currently working on her dissertation (English) at the University of British Columbia. 